\title{
The Measurement of Growth under Embodied Technical Change*
}

Omar Licandro

European University Institute and FEDEA

Javier Ruiz-Castillo Universidad Carlos III de Madrid

Jorge Durán

Universidad de Alicante

\section{Introduction}

The well-known Kaldor stylized facts have guided from the sixties the research agenda on economic growth, giving empirical support to the neoclassical growth theory. Most of the developments of this theory are based on the one-sector Solow-Ramsey model, which predicts that the economy converges to a balanced growth path (BGP) where, among other things, relative prices are constant, all components of aggregate demand grow at the same rate, and the capital-output ratio stays unchanged.

However, new evidence from National Income Product Accounts (NIPA) for the U.S. published by the Bureau of Economic Analysis (BEA) contradicts some of the predictions of the neoclassical growth model. Over the last decades, the U.S. economy shows the following pattern :

1. A permanent decline in the price of equipment investment relative to the price of non durable consumption.

2. A permanent increase in the ratio of real equipment investment to real GDP, and, consequently, a long-run growth rate of equipment investment larger than the long-run growth rate of non durable consumption.

\footnotetext{
* The authors have benefited from comments of Raouf Boucekkine, Fernando del Rio, Berthold Herrendorf Juan Francisco Jimeno Michol Reiter and an anu Bouse re

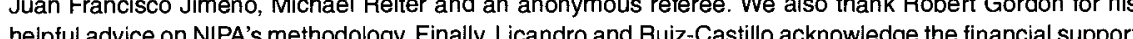
of the Spanis Ministry of Sciences and Technology (SEC2000-0260 and SE2000-0173, respectively). of the Spanish Mrón 1999-00410) at CEPREMAP. Correspondence author: Omar
} 
These two facts call for a reformulation of modern growth theory in order to generate predictions consistent with the new evidence. As stated in Whelan (2001), such a reformulation requires a multisector dynamic general equilibrium model. A first step in this direction is the two-sector version of the optimal growth model proposed in Greenwood, Hercowitz and Krusel (1997), hereafter GHK. The first sector produces one non durable good, which is used both for consumption and as an input for the production of durable goods. This sector benefits from disembodied technological change. The second sector produces one durable good which is only used for investment, and it benefits from an additional source of technological progress, the so-called embodied technical change. This is the simplest way of accommodating the permanent decline in the relative price of equipment, and having predictions consistent with fact 2 .

This paper raises the fundamental question of how to aggregate consumption and investment in a common measure of real output in the framework of such a two-sector optimal growth model. The economic theory of index numbers, which is at least as old as consumer theory, has addressed the problem of aggregating different final goods in an index of real output. ${ }^{1}$ In this literature, a quantity index for an individual agent is obtained by evaluating two bundles of goods at different moments in time in terms of the agent's preferences for these goods. In order to differentiate it from other types of quantity indexes, such an index is called a "true quantity index". Fisher and Shell (1971) have extended this notion to the case in which preferences are time dependent. In order to apply index number theory in a two-sector optimal growth model, this paper argues that intertemporal preferences for a representative agent can be represented by an indirect utility function of current consumption and investment. Since such preferences are time dependent, following Fisher and Shell (1971) a true index of real output growth can be defined.

In evaluating the quantitative properties of their model, GHK argue that for "growth accounting" output can be identified with the production in the non durable sector. But this measure of real output growth differs from the one published by the BEA according to NIPA conventions. Such a discrepancy has theoretical and quantitative implications. In particular, it affects the estimation of the contribution of embodied technical change to the growth rate of per-capita output.

In this paper, a true quantity index is applied to the measurement of real output growth in a simplified version of the two-sector growth model proposed by GHK. Parameters are calibrated to the U.S. economy as close as possible to GHK's calibration, and the proposed true index of real output growth is computed. The main findings are the following two. First, NIPA's methodology leads to a very good approximation to our true index of real output growth. Second, once real output growth is appropriately measured, it is found that embodied technical change accounts for $69 \%$ of per capita

\footnotetext{
1 Diewert $(1981,2001)$ are good surveys on the economic theory of index numbers.
}

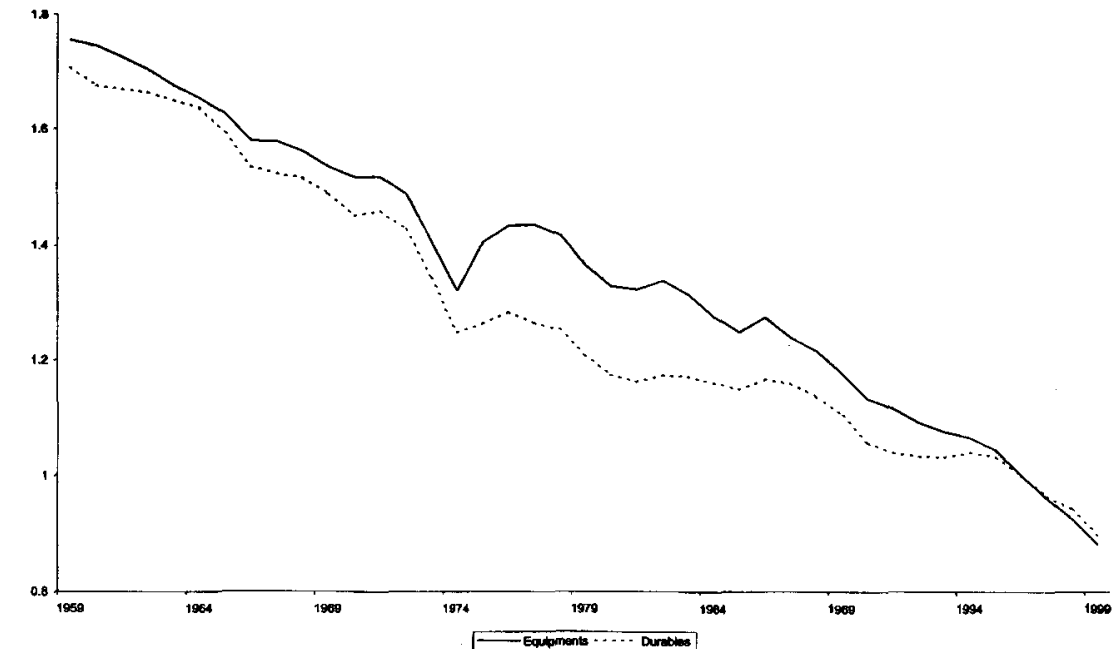

Figure 1: Equipment investment and durable consumption prices relative to non durable consumption prices. Source : BEA.

GDP growth in the U.S., a larger contribution than the $58 \%$ found in GHK This result reinforces the GHK's claim that embodied technical change is important for growth.

The paper is organized as follows. Section 2 describes the facts. A simplified version of the GHK's model is presented and solved in Section 3 In Section 4, the aggregation problem is analyzed and, based in the economic theory of index numbers, a true index of real output growth is proposed The quantitative implications of using this index are discussed in Section 5 , where the contribution of embodied technical change to U.S. per capita growth is estimated. Finally, conclusions and extensions are discussed in Section 6 .

\section{New Evidence}

Concerning the first of the two facts referred to in the Introduction, Figure shows the evolution of the relative price of durable consumption and equipment investment in NIPA relative to the price of non durable consumption. The observed decline in the relative price of equipment is a clear evidence of a permanent improvement in the efficiency of the durable goods sector relative to the non durable sector. This phenomenon has been called embodied technical change, since new investments are required in order to profit from the progress in technology. From an empirical perspective, this fact is closely related to the introduction of quality adjustments in the measurement of prices and quantities in NIPA. In particular, the introduction of 


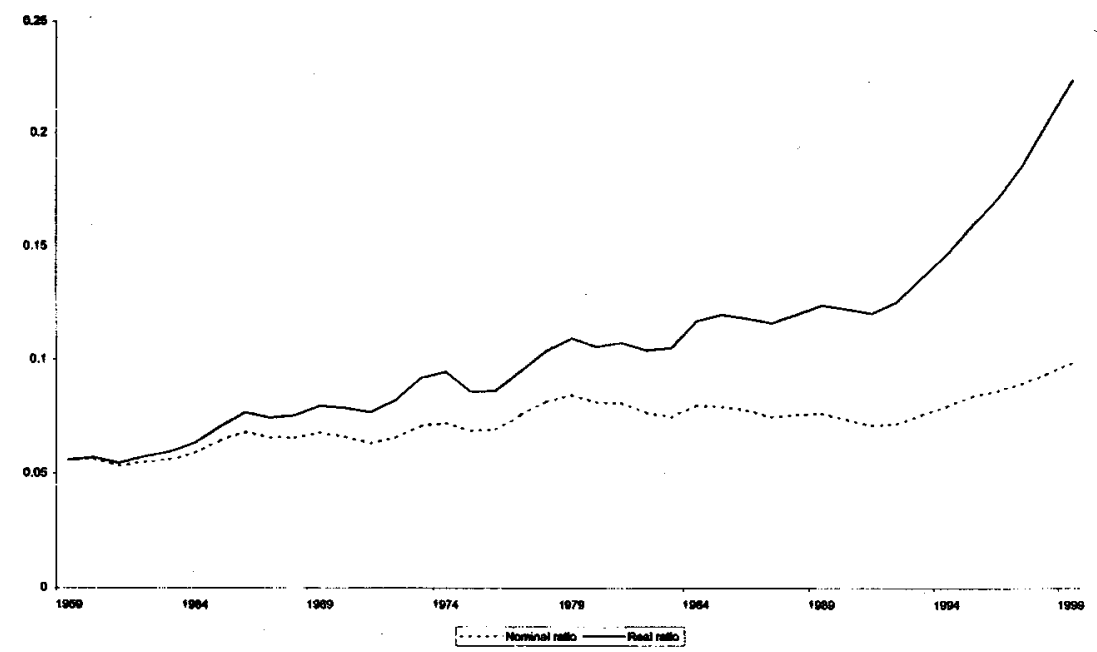

Figure 2: The ratio of equipment and software to $G D P$, in nominal and real terms. Source : BEA.

hedonic prices in NIPA's methodology for computers is at the basis of the observed decline in the relative price of equipment. From 1969 to 1999 , the relative price of computers has declined at the cumulative rate of $20 \%$ per year, which explains most of the $1.8 \%$ annual decline in the relative price of equipment.

Figure 2 shows the evolution of both the real (continuous line) and the nominal (dotted line) equipment to GDP ratios. Both lines coincide in 1959, which has been taken as the base year. The important observation, fact 2 in the Introduction, is that the real ratio diverges from the nominal one. In 1999, the nominal ratio is around $10 \%$, but the real ratio is around $22 \%$, more than twice as large. ${ }^{2}$ Under embodied technical change, even if the equipment investment share on nominal GDP is stable, the ratio of real equipment to real GDP is increasing over time. When equipment investment benefits from embodied technical change, real equipment grows faster than GDP implying that the real equipment to GDP ratio increases. According to new NIPA measurements, the output-capital ratio is non stationary but permanently decreasing, which contradicts one of the Kaldor stylized facts.

Specifically, as Table 1 shows, equipment investment is growing faster than GDP, and GDP is growing faster than non durable consumption.

2 As Whelan (2000) points out, this ratio must be carefully interpreted, because chained quantity indexes actually employed in NIPA are non additive. In particular, the real investment ratio is no longer a share, and it can become larger than unity if the relative price of equipment continues to decline.
Table 1 : Annual growth rates (in \%) for 1969/1999

\begin{tabular}{ll} 
Non durable consumption & 2.55 \\
GDP & 3.08 \\
\hline
\end{tabular}

Equipment investment $\quad 6.68$

\section{Growth under Embodied Technical Change}

The new evidence on the U.S. growth patterns during the last decades of the 20th century calls for a reformulation of the modern theory of growth. A first and important attempt in this direction is in GHK. These authors propose a two sector version of the optimal growth model with embodied technical change. A simplified version of this model can be represented by the following planner's problem:

$$
\max \sum_{t=0}^{\infty} \frac{c_{t}^{1-\sigma}}{1-\sigma} \beta^{t},
$$

$$
\begin{gathered}
z_{t} k_{t}^{\alpha}=c_{t}+\iota_{t} \\
i_{t}=q_{t} \iota_{t} \\
k_{t+1}=(1-\delta) k_{t}+i_{t} \\
q_{t+1}=\left(1+\gamma_{q}\right) q_{t} \\
z_{t+1}=\left(1+\gamma_{z}\right) z_{t},
\end{gathered}
$$

given $k_{0}>0, q_{0}=1$, and $z_{0}=1$. The endogenous variables $c_{t}, \iota_{t}, i_{t}$ and $k_{t}$ are in per capita terms. Equation (2) is the feasibility constraint in the non durable sector: technology is Cobb-Douglas, and non durable production is allocated to consumption, $c_{t}$, and as an input in the production of equipment, $\iota_{t}$. The variable $z_{t}$ is total factor productivity in the non durable sector, and $\gamma_{z}$ is the rate of disembodied technical change. From (3), technology in the investment goods sector is linear, with productivity $q_{t}$. Technological progress also affects the investment goods sector, with $\gamma_{q}$ being the rate of embodied technical change. Equation (4) is the law of motion for capital. Investment $i_{t}$ and capital $k_{t}$ are measured in units of the durable good, and consumption $c_{t}$ is measured in units of the non durable good. Concerning parameters, $\alpha$ is the capital share, $\delta$ is the depreciation rate of capital, $\beta$ is the time preference parameter, and $\sigma$ is the inverse of the intertemporal elasticity of substitution.

In addition, GHK (i) distinguish two types of investment goods, structures and equipment, (ii) assume that preferences are also defined on leisure, and (iii) introduce taxes. The version presented in this paper selects the minimum assumptions required to reproduce the evidence presented in Section 2. 
The Euler equation associated to this problem is :

$$
\left(\frac{c_{t+1}}{c_{t}}\right)^{\sigma}=\frac{\beta}{1+\gamma_{q}}\left(1-\delta+\alpha z_{t+1} q_{t+1} k_{t+1}^{\alpha-1}\right)
$$

Given the exogenous process of technological progress, the equilibrium of this economy is thus characterized by equations (2) to (5) and the initial condition $k_{0}>0$. This model is consistent with fact 1 in the Introduction, since the relative price of equipment, $\frac{1}{q_{t}}$, declines permanently at the rate $\gamma_{q}$. It is very important to notice that, if $\gamma_{q}$ is calibrated as the decline rate of equipment prices in NIPA relative to non durable consumption, then $i_{t}$ and $k_{t}$ should be measured in the same units as real investment and the capital stock in NIPA.

Along the BGP, non durable consumption grows at the rate

$$
1+g_{c}=\left(1+\gamma_{z}\right)^{\frac{1}{1-\alpha}}\left(1+\gamma_{q}\right)^{\frac{\alpha}{1-\alpha}},
$$

and the growth rate of investment is

$$
1+g_{k}=\left(1+\gamma_{z}\right)^{\frac{1}{1-\alpha}}\left(1+\gamma_{q}\right)^{\frac{1}{1-\alpha}}>1+g_{c}
$$

In agreement with fact 2 in the Introduction, GHK's model predicts that the long-run growth rate of equipment investment is larger than the long-run growth rate of non durable consumption.

In this framework, consumption and investment are different goods. Prices can be used to aggregate them in nominal terms. In what follows, the non durable good is taken as the numeraire. Thus, the price of the non durable good is constant over time and equal to unity, while the price of the durable good is equal to $\frac{1}{q_{t}}$. Using these prices, consumption and investment can be aggregated in a common measure of nominal output:

$$
c_{t}+\frac{1}{q_{t}} i_{t}=c_{t}+\iota_{t}
$$

When the non durable good is taken as the numeraire, $c_{t}$ and $\iota_{t}$ measures nominal consumption and investment, respectively, and total production in the non durable sector is equal to nominal output. However, real consumption, $c_{t}$, and real investment, $i_{t}$, are measured in different units, and the problem of measuring real output remains open. The aim of the next section is to propose a measure of real output growth consistent with preferences in (1).

\section{The Measurement of Real Output Growth}

GHK claim that for "growth accounting" real output should be identified with the production in the non durable sector. In order to calibrate their model, measurements of both sources of technological progress, embodied and disembodied, are required. They use the series of durable prices estimated by Gordon (1990) as an appropriate measure of $q_{t}$. In order to measure disembodied technical change, they proceed in the following way. First, they take nominal consumption and investment from NIPA, and they deflate them using the NIPA's price index of non durable consumption in order to obtain measurements of $c_{t}$ and $\iota_{t}$. Second, given their measurements of $q_{t}$ and $\iota_{t}$, they use equations (3) and (4) to compute series for $i_{t}$ and $k_{t}$. Finally, disembodied technical change is derived from equation (2), using the constructed series of $c_{t}+\iota_{t}$ and $k_{t}$. In this sense, output in the non durable goods sector, $c_{t}+\iota_{t}$, is a useful concept for growth accounting because it allows for a consistent estimation of disembodied technical change. However, as it is shown in the next section, it does not provide an appropriate measurement of real output.

\subsection{Index Number Theory}

The economic theory of index numbers was developed to provide theoretical foundations for the construction of price and quantity indexes. It assumes that individuals have well defined preferences on a commodity space, and that they optimally allocate a given amount of income to the consumption of these goods at given prices. The problem is purely static, in the sense that current income cannot be transferred to the future. ${ }^{3}$

Suppose for simplicity that an agent has access to two different goods, which he consumes in quantities $x_{t}=\left(x_{t}^{1}, x_{t}^{2}\right)$ in period $t$. Preferences are represented by the continuous utility function $U\left(x_{t}^{1}, x_{t}^{2}\right)$, increasing in both arguments and concave. Given nominal prices $p_{t}=\left(p_{t}^{1}, p_{t}^{2}\right)$ and nominal income $Y_{t}$, the solution of the agent's problem in each period $t$ is

$$
u\left(p_{t}, Y_{t}\right)=\max _{\left\{x_{t}\right\}} U\left(x_{t}\right)
$$

st.

$$
p_{t} x_{t}=Y_{t}
$$

The optimal utility level $u($.$) depends on nominal income and prices. The$ dual associated to this problem is

$$
\kappa\left(p_{t}, w\right)=\min _{\left\{x_{t}\right\}} p_{t} x_{t}
$$

st.

$$
U\left(x_{t}\right)=w,
$$

3 Pollak (1975) is an exception. He extends the standard theory of the cost of living index to a multiperiod setting. More recently, Reiter (1999) proposes true quantity indexes for real wealth and real savings in a similar framework. 
where $\kappa\left(p_{t}, w\right)$ is the so-called cost function, and represents the minimum cost required to achieve a given level of utility $w$ at prices $p_{t}$. Under the assumptions made on consumer preferences, $Y_{t}=\kappa\left(p_{t}, u\left(p_{t}, Y_{t}\right)\right)$ for all $t$.

Suppose that prices, nominal income and consumption allocations $p_{i}, Y_{i}$ and $x_{i}$, respectively - are observed for two adjacent periods, $i=t-1, t$. In order to compare the quantity vectors $x_{t-1}$ and $x_{t}$ in terms of the utility levels they provide in each situation, $w_{i}=u\left(p_{i}, Y_{i}\right)$ for $i=t-1, t$, a reference price vector must be selected. For example, take current prices as reference prices and compute the minimum cost of obtaining past utility, $w_{t-1}$, at those prices, $Y_{t-1}^{*}=\kappa\left(p_{t}, w_{t-1}\right)$. Thus, the variable $Y_{t-1}^{*}$ measures the minimum income required at reference prices to achieve the utility level that the agent obtained at past prices and income. The true quantity index $Q\left(x_{t}, x_{t-1} ; p_{t}\right)$ defined by

$$
Q\left(x_{t}, x_{t-1} ; p_{t}\right)=\frac{\kappa\left(p_{t}, w_{t}\right)}{\kappa\left(p_{t}, w_{t-1}\right)}=\frac{Y_{t}}{Y_{t-1}^{*}}
$$

provides a measure of real income change at reference prices $p_{t}$.

In many economic problems, including the growth model in this paper, the relevant preference map is time dependent. Fisher and Shell (1971) have extended the definition of price and quantity indexes to a situation where preferences change over time. Let the utility function be $U_{t}\left(x_{t}\right)$, which implies that the optimal utility level $u_{t}\left(p_{t}, Y_{t}\right)$ and the cost function $\kappa_{t}\left(p_{t}, w\right)$ are both time dependent. The problem is to compare the optimal output vectors $x_{t-1}$ and $x_{t}$, chosen at different price vectors and money incomes, $p_{i}$ and $Y_{i}$ for $i=t-1, t$, respectively. Notice that the corresponding optimal utility levels are evaluated in terms of each situation's preferences: $w_{t-1}=u_{t-1}\left(p_{t-1}, Y_{t-1}\right)$ and $w_{t}=u_{t}\left(p_{t}, Y_{t}\right)$. Fisher and Shell suggest to compare the two situations in terms of current preferences. ${ }^{4} \mathrm{De}$ fine $\hat{w}_{t-1}=u_{t}\left(p_{t-1}, Y_{t-1}\right)$, the utility that could be achieved with yesterday budget constraint according to today's preferences. Let $Y_{t-1}^{\mathcal{F}}=\kappa_{t}\left(p_{t}, \hat{w}_{t-1}\right)$ be the minimum income necessary to obtain the utility level $\hat{w}_{t-1}$ at current prices. In Fisher and Shell own words, $Y_{t-1}^{\mathcal{F} S}$ measures "How much income is required "today" to make me indifferent between facing yesterday's budget constraint and facing ... today's prices and the income in question." Recall that $Y_{t}=\kappa_{t}\left(p_{t}, w_{t}\right)$ is the minimum income necessary to attain the optimal utility level $w_{t}$ at current prices. Taken current prices as reference prices, the Fisher-Shell true quantity index $\mathcal{F} \mathcal{S}_{t}\left(x_{t}, x_{t-1} ; U_{t}, p_{t}\right)$ is defined by

$$
\mathcal{F S}_{t}\left(x_{t}, x_{t-1} ; U_{t}, p_{t}\right)=\frac{\kappa_{t}\left(p_{t}, w_{t}\right)}{\kappa_{t}\left(p_{t}, \hat{w}_{t-1}\right)}=\frac{Y_{t}}{Y_{t-1}^{\mathcal{F} S}}
$$

and provides a measure of real income change. The Fisher-Shell true quantity index compares, in terms of today preferences $U_{t}$, the minimum cost

\footnotetext{
${ }^{4}$ Comparisons could also be done in terms of past preferences. However, Fisher and Shell find it "natural" to
} use current preferences, since evaluations are made today, not yesterday. of acquiring the consumption bundles $x_{t}$ and $x_{t-1}$, at reference prices $p_{t}$. For example, if $\mathcal{F S}_{t}>1$, then at current prices and current preferences the minimum income required to achieve today's optimal utility level $w_{t}$ is larger than that required to achieve the utility level $\hat{w}_{t-1}$, indicating that there has been an increase in real income. ${ }^{5}$

\subsection{Value Function and Indirect Utility}

In GHK's growth model, a representative agent owns an initial stock of capital and an endowment of labor. At each time $t$, he produces consumption and investment goods in order to consume today and accumulate capital for future production. His preferences in (1), however, are defined on the space of intertemporal consumption flows. In order to apply index number theory, intertemporal preferences can be represented by an indirect utility function defined on current consumption and investment. Consider the Bellman representation of the problem:

$$
v\left(q_{t}, z_{t}, k_{t}\right)=\max _{\left\{c_{t}, i_{t}\right\}} \frac{c_{t}^{1-\sigma}}{1-\sigma}+\beta v\left(q_{t+1}, z_{t+1}, k_{t+1}\right)
$$

st.

$$
\begin{gathered}
z_{t} k_{t}^{\alpha}=c_{t}+\frac{i_{t}}{q_{t}} \\
k_{t+1}=(1-\delta) k_{t}+i_{t},
\end{gathered}
$$

where $v\left(q_{t}, z_{t}, k_{t}\right)$ is the value function. The right hand side of the Bellman equation can be interpreted as the maximization of an indirect utility function on current consumption and investment :

$$
U_{t}\left(c_{t}, i_{t}\right)=\frac{c_{t}^{1-\sigma}}{1-\sigma}+\beta v\left(q_{t}\left(1+\gamma_{q}\right), z_{t}\left(1+\gamma_{z}\right),(1-\delta) k_{t}+i_{t}\right)
$$

The indirect utility function is time dependent, since it depends on current states $q_{t}, z_{t}$, and $k_{t}$. Along the BGP the value function takes the following form

$$
v\left(q_{t}, z_{t}, k_{t}\right)=v^{S}\left(q_{t}, z_{t}, k_{t}\right) \equiv \Lambda \frac{\left(z_{t} k_{t}^{\alpha}-\left(\delta+g_{k}\right) \frac{k_{t}}{q_{t}}\right)^{1-\sigma}}{1-\sigma}
$$

where

$$
\Lambda=\left(1-\beta\left(1+g_{c}\right)^{1-\sigma}\right)^{-1}
$$

${ }^{5}$ Naturally, such an increase in real income will be different if the evaluation of the minimum cost to achieve these utility levels is done at a different price vector, say $p_{t-1}$, or if the evaluation is made at "past" preferences. 
Using such indirect utility function, index number theory can now be applied to compute the rate of real output growth.

\subsection{The $\mathcal{F S}$ Index of Real Output Growth}

Let the economy be in its BGP at least from time $t-1$, and let the non durable good be the numeraire. Prices at time $t$ are given by the vector $p_{t}=\left(1, \frac{1}{q_{t}}\right)$, and $Y_{t}=z_{t} k_{t}^{\alpha}$ is nominal income in per capita terms. Denote by $x_{t}=\left(c_{t}, i_{t}\right)$ an allocation at time $t$. The indirect utility function $U_{t}\left(x_{t}\right)$ in equation (9) is time dependent. In order to compute a true quantity index according to Fisher and Shell, comparisons must be done in terms of today's preferences. Taking prices $p_{t}$ as reference prices, a Fisher-Shell true quantity index to measure real output growth in the GHK economy, $\mathcal{F S}_{t}\left(x_{t}, x_{t-1} ; U_{t}, p_{t}\right)$, can be defined as in equation (6).

To actually compute $\mathcal{F} \mathcal{S}_{t}$, the utility function $U_{t}\left(c_{t}, i_{t}\right)$ can be evaluated near the BGP. For that purpose, in equation $(9) v($.$) can be substituted$ for its expression in (10). Given this parametric function $U_{t}($.$) , the cost$ function $\kappa_{t}($.$) and the utility levels w_{t}$ and $\hat{w}_{t-1}$ can be computed.

It can be easily proved that $Y_{t-1}^{\mathcal{F} S}<Y_{t-1}$, which implies that $\mathcal{F S}_{t}>$ $1+g_{c}$. Notice that production measured in units of the non durable good is growing at the rate $g_{c}$. However, because capital is cheaper today than it was yesterday, if yesterday's firms had access to today's prices, they could have obtained the realized $t-1$ level of utility with less production than they actually undertook (because they wouldn't have had to allocate so much resources to purchasing capital). For this reason, the Fisher-Shell index gives a larger measure of output growth than the growth rate of consumption. This result has important consequences for the measurement of growth, because measuring real output in units of the non durable good does not take into account the increase in efficiency due to the embodied nature of technical progress

\section{Calibration}

\subsection{Measuring Real Output Growth}

In order to measure real growth, the model is calibrated as close as possible to GHK' calibration. The following parameter values are taken directly from GHK : $\alpha=0.17, \beta=0.95, \gamma_{q}=0.0321, \gamma_{z}=0.0039, \delta=0.124$ and $\sigma=$ $.999 .^{6}$ Along the BGP, the growth rate of consumption is $g_{c}=0.0112$ and the growth rate of investment is $g_{k}=0.0437$. The growth rate of consumption is

6 in GHK, consumption preferences are represented by a logarithmic function. here slightly smaller than in GHK, because structures are excluded. Nominal output shares are $\frac{c_{t}}{y_{t}}=0.87$ and $\frac{\iota_{t}}{y_{t}}=0.13$, where $y_{t}$ is nominal production (i.e., production in the non durable sector).

Using NIPA's methodology, the chained Fisher index gives an annual growth rate in real terms of $1.532 \%$ along the BGP. ${ }^{7}$ The Fisher-Shell quantity index of output growth is $1.524 \%$ per year, very close to the NIPA measurement. In addition, both the $\mathcal{F S}$ and the NIPA growth rates have been computed for different values of $\sigma$ in the interval $[.01,10]$. The $\mathcal{F S}$ growth rate ranges in the $[1.366,1.558]$ interval, in percentage points, but it is in all cases very close to the corresponding NIPA measurement. It must be concluded that NIPA's methodology provides an appropriate measurement of real output growth in this framework.

\subsection{The Contribution of Embodied Technical Change}

The main result in GHK is the estimation of the contribution of embodied technical change to per capita real output growth. By assuming that real GDP must be measured in units of the non durable good, they actually measure the contribution of embodied technical change to the growth of per capita output only in the non durable goods sector. However, as it has been argued in this paper, NIPA gives a more accurate measurement of the growth rate of per capita real output, which calls for a new estimation of the contribution of embodied technical change.

First, in our simplified version of the GHK's model, the contribution of embodied technical change to the growth rate of per capita real output in the non durable goods sector is estimated as $58 \%$. This is a very good approximation to the contribution of embodied technical change reported in GHK. Second, when NIPA's methodology is used to measure real output growth, the contribution of embodied technical change to the growth rate of per capita output is raised to $69 \%$. The reason is that in NIPA's methodology the growth rate of real output is a weighted average of the growth rate of consumption and the growth rate of investment. The weights are approximately equal to the corresponding shares on nominal output. Therefore, the growth rate of real output is approximately equal to the growth rate of rea consumption plus $s \gamma_{q}$. This is a pure contribution of embodied technical change, which is not taken into account when real output is measured in units of the non durable good.

\footnotetext{
7 The chained Laspeyres quantity index of output growth is $\mathcal{L}=\left(1+g_{c}\right)\left(1+\gamma_{q} s\right)$, the chained Paasche quantity index is $\mathcal{P}=\left(1+g_{c}\right)\left(1+\gamma_{q}(1-s)\right)^{-1}$, while the chained Fisher quantity index is a geometric mean of both : $\mathcal{F}=(\mathcal{L} \mathcal{P})^{\frac{1}{2}}$
} 


\subsection{Conclusions and Extensions}

New U.S. evidence from NIPA contradicts some of the well-known Kaldor stylized facts, and calls for a reformulation of the modern theory of economic growth. Among the new facts, two must be stressed: A permanent decline in the relative price of durable goods, and a permanent increase in the real equipment to real GDP ratio. In order to be consistent with these new facts, growth models must contain at least two sectors. Consequently, the problem of defining aggregate output must be addressed. The definition of real output growth proposed in this paper is in accordance with the economic theory of index numbers, and it follows closely Fisher and Shell's (1971) proposal.

A simplified version of GHK model is calibrated on U.S. data and the Fisher and Shell index of real output growth is computed. The first finding is that NIPA's methodology measures growth consistently with a FisherShell true quantity index. Secondly, when the growth rate is measured as in NIPA the contribution of embodied technical change to per capita GDP growth in the U.S. is of around $69 \%$, larger than the $58 \%$ found by GHK. In this sense, this paper reinforce the GHK's claim that embodied technical change is important for growth.

The GHK model constitutes an important step for the reconciliation of the modern growth theory with the new evidence. However, these new facts call for a more general framework, since new NIPA's data indicate that embodied technical change also affects durable consumption. Therefore, in line with Whelan (2001), the following step is to extend the growth model with embodied technical change in order to include durable consumption and services. This would allow for a permanent substitution of durable services for non durable consumption. In the far future we will still eat potatoes, but robots will cook them for us.

\section{References}

Diewert, W. (1981), "The Economic Theory of Index Numbers : A Survey", in A. Deaton, ed, The Theory and Measurement of Consumer Behavior: Essays in Honor of Sir Richard Stone, Cambridge University Press.

Diewert, W. (2001), "The Consumption Price Index and Index Number Theory : A Survey", Department of Economics, The University of British Columbia, DP 01-02, http : //web.arts.ubc.ca/econ.

Fisher, F. and Shell (1971), "Taste and quality change in the pure theory of the true-cost-of-living index", in Z. Griliches, ed, Price indexes and quality change, Harvard University Press.

Gordon, R. J. (1990), The measurement of durable goods prices, Chicago University Press.

Greenwood, J., Z. Hercowitz and P. Krusell (1998), "Lung-run implications of investment-specific technological change", American Economic Review, 87, 342-362.

Pollak, R (1975), "The intertemporal cost of living index", Annals of Economic and Social Measurement, 4, 179-195.

Reiter, M. (1999), "Asset prices and the Measurement of Wealth and Saving", Universitat Pompeu Fabra, WP 396.

Whelan, K. (2000), "A guide to the use of chain aggregated NIPA data", Federal Reserve Board, DP 2000-35.

Whelan, K. (2001), "A two sector approach to modelling U.S. NIPA data", Federal Reserve Board, DP 2001-4. 